\title{
Perfecting the Grain Reserve System
}

\author{
Xiao-Dong GUO \\ Center for Food Security and Strategic Studies, Nanjing University of Finance and Economics, Nanjing, Jiangsu, China
} (guoxd@njue.edu.cn)

\begin{abstract}
Grain reserve system is an important material basis of national control of grain. Grain reserve system is still a lot of problems in the system, mechanism, structure and layout. We should solve the way of making clear the starting point of the op erating reserve grain, optimizing the size of the National Grain Reserve, optimizing the layout of the grain reserve pool, and improving the system of the grain reserve system.
\end{abstract}

Keywords - Grain, reserve, Strategies

\section{完善粮食储备体系的对策探讨}

郭晓东

南京财经大学粮食安全与战略研究中心, 南京, 江苏, 中国

摘 要 粮食储备体系是国家粮食宏观调控的重要物质基础。粮食储备体系目前在体制、机制、结构、布局诸多方面仍然存在不 少问题。应通过明确经营储备粮的出发点、优化国家粮食储备规模、优化粮食储备库点布局、完善粮食储备体制机制等途径加以解 决。

关键词 粮食, 储备, 对策

\section{1. 引言}

粮食储备体系的建立, 是国家粮食宏观调控的重要物 质基础, 成为国家宏观调控的有力手段和依靠力量。新中 国成立以来, 在粮食统购统销时期建立过 “506”、“甲字粮” 等战略储备。在改革开放的新形势下, 特别是在农村改革 的推动下, 我国粮食综合生产能力大幅度提升。中央政府 在吸取历史经验、结合国情引进吸收国外经验与技术的基 础上, 抓住 1990 年粮食丰收、粮食产量上了新台阶的有利 时机, 因势利导, 首先建立了中央专项粮食储备制度。通 过多年的持续努力, 形成了以中央储备粮为核心, 地方储 备粮为支柱, 社会储备粮 (企业和农民储备) 为基础的三 级粮食储备体系, 创立了中国现代粮食储备制度的新模式。 实践证明, 中国粮食储备体系是有巨大承受力和顽强生命 力的, 今后它将继续在保障我国粮食安全和稳定世界粮食 市场中发挥积极、可靠的作用。经过不断改革, 在取消粮
食统购统销以后, 粮食流通进入了社会主义市场经济的新 时期。现在国有粮食流通行业的大部分精华集中于储备体 系, 如果没有这个体系, 改制后的国有粮食流通企业可能 会荡然无存, 不会有今天的新局面。现在, 它正与异军突 起的民营粮食企业以及进入我国的外资粮食企业一起，担 负着全社会的供应任务, 形成多渠道、多元化的粮食流通 新格局, 在国家粮食宏观调控制度下, 共同维护国家粮食 安全, 保障社会粮食供应, 保持粮食市场的稳定。现在, 在我国要不要建立粮食储备体系的问题, 已经从上到下形 成了广泛共识, 而如何改进发展、完善储备体系, 使之更 好地发挥作用, 已成为当务之急。

\section{2. 粮食储备体系的现存问题}

粮食储备工作的重点已从要不要粮食储备, 转到如何 进一步搞好储备工作上。粮食储备体系正如其他新生事物

粮食公益性科研专项（N0. 201513004）；国家粮食公益性科研专项（项目编号：2013130009-01）；江苏高校优势学科建设工程 资助项目（PAPD）；南京财经大学粮食安全与战略研究中心 2014 年度重大项目预研究招标课题（项目编号 CFSSS2014-07)。 
一样, 目前在体制、机制、结构、布局诸多方面仍然存在 不少问题。

\section{1 我国粮食储备体系功能定位问题}

政府储备的基本目标有 4 个: 粮食安全目标, 稳定收 入目标, 稳定价格目标和提高效益目标, 成为构建国家粮 食储备体系与系统模式的基础。在粮食储备体系的多重目 标中, 粮食安全供给是主导目标, 稳定收入、稳定价格、 提高效益则是衍生目标。

对于价格稳定这一目标, 国内一些学者认为用建立储 备的方式来稳定价格, 很快就会滑入只进不出的单行线, 储备制度将变为价格支持政策, 国家将背上日益沉重的负 担。不仅如此, 如果平抑价格的结果导致季节差价过小, 周转储备无利可图甚至亏本, 就会促使商业机构减少自身 用于周转的库存, 使得周转储备也依赖于国家, 更加重了 补贴负担。从近几年国家粮食储备运行情况看, 价格支持 日益成为专项储备的主要目标, 粮食储备的基本目标因偏 离保障粮食安全需要而出现错位。例如, 粮食专储应于丰 收年份吞入, 而歉收年份吐出, 因而起到平抑粮价的作用, 但是这客观上助长了各级政府争储备指标、争补贴, 把专 储制度当作价格支持与收入支持的手段, 使他们可能以社 会安定为理由争专储补贴, 对供应的安全保障却很少关心。 在这种情况下, 不仅地方政府和粮食部门不关心专储粮食 的数量、品种、质量, 不积极推陈储新, 甚至以陈次粮抵 充专储粮。长此以往, 许多地方的专储粮食就有可能账存 实亡, 或者粮食虽在但已丧失食用价值, 从而彻底违背建 立储备制度的初衷。

\section{2 粮食储备体系的规模问题}

联合国世界粮农组织规定, 一国粮食安全储备应为这 个国家一年粮食消费量总和的 $17 \%-18 \%$, 其中: 周转储备 量为 $12 \%$, 后备库存量为 $5 \%$ 。6 \% 近几年, 国际上出现了 减少国家储备规模的趋势, 各国不同程度地减少了政府储 备的规模, 对国际市场和社会储备的依赖程度不断增加。

自进入 21 世纪以来, 我国的粮食储备量一直远高出最低合 理储备规模, 使得粮食储备体系运行成本过大、储备时间 过长、轮换运转不畅等削弱粮食储备效能的负面因素相伴 而生。

\section{3 储备粮布局问题}

从储备粮的地区分布来看, 我国的粮食储备主要集中 在主产区, 且其所占比重极大, 13 个主产区约占全国粮食
储备总量的 $72 \%$ 左右, 销区和其他地区占 $28 \%$ 左右。黑龙江、 吉林、河南三省的库存量占全国库存总量的 $1 / 3$, 有 9 个 省份占全国库存总量的 $1 / 3$, 其余省份占全国库存总量的 $1 / 3$ 。（虽然在粮食供大于求时, 这样的布局有利于粮食的 收购, 但是在粮食供给紧张时, 却会对销区的粮食安全造 成严重的威胁。同时有相当多的中央储备粮承储库点与地 方商品粮在同一个库点一起进行管理, 监管难度较大, 使 主管部门难以了解中央储备粮库的真实情况。

\section{4 粮食储备的运作机制问题}

目前, 我国存在中央、省、市、县四级储备并存的格 局。多元主体不利于分清责任, 易发生利益冲突, 影响储 备粮调控作用的充分发挥。如, 当市场粮价全面上涨, 中 央动用专项储备向市场抛售粮食平抑市场波动时, 许多地 方粮食部门的实际操作却与中央背离从中获益; 当执行保 护价收购粮食时, 会出现一个地区按保护价收购而其它地 区不按保护价收购的情况, 使执行该政策的地区负担加重, 地方政府感到吃亏, 缺乏执行该政策的积极性, 甚至不执 行。一些储粮企业甚至逆向调节, 在粮食价格暴涨时, 储 备企业本应抛出平抑粮价, 却舍不得卖出, 期望为自己的 “小金库” 赚更多的钱, 有时干脆自己卖自己买, 搞 “转 圈粮” 糊弄上级; 反之, 在粮食价格下跌时却强调库存爆 满, 有的甚至推波助澜, 清仓压库, 逃避责任, 完全失去 了国有粮食库存的冞莱平准作用。再如, 我国储备粮的粮 权在国务院, 具体负责行政管理的是国家粮食局, 此外, 这项工作还涉及国家发改委、财政部、中国农业发展银行 和中国储备粮管理总公司等几个部门。储备粮的吞吐需要 由这些部门研究同意后, 再报国务院批准, 然后由这些部 门下达给有关企业来执行。当国内粮食市场出现波动往往 会因为部门之间意见不一致, 错过最佳调控时机, 难以形 成对市场的正面推动力。同时, 承储企业无轮换经营权, 层层审批后往往失去 “商机”。轮换费用难以落实到基层承 储企业, 轮换资金没保证, 轮出轮入的价格政策不明确, 在近年粮食市场价低于国家保护价较多的情况下, 使得承 储企业难以进行正常轮换。图与表放在该栏的顶部或尾部, 避免将它们放在一栏的中间, 图与表的宽度尽量不要超过 栏宽。确实大的图或表可以跨栏放置。图题应该居中放在 图的下面, 表题应该居中放在表的上面。避免将图或表放 在提及的段落之前。 


\section{3. 问题解决思路}

\section{1 明确经营储备粮的出发点}

在粮食储备体系的多重目标中, 粮食安全供给是主导 目标, 稳定收入、稳定价格、提高效益则是衍生目标。中 国粮食储备体系, 作为宏观调控重要手段的储备粮, 更具 有战略性、公益性的特征。从这个根本点出发, 经营储备 粮必须从国家的经济全局出发, 维护国家粮食安全, 稳定 粮食市场, 既要讲求经济效益, 更要注重社会效益; 既要 注意搞活企业, 更要服从国家的宏观调控政策; 既要市场 运作, 更要承担社会责任, 为 “三农” 服务, 为城镇粮食 供应服务, 为保障军需民食服务。离开这个根本点, 粮食 储备就会走偏方向。

\section{2 合理确定国家粮食储备规模}

一个国家的粮食储备规模是受粮食生产、农业发展、 人口、自然气候变化、国际风云形势等许多因素影响的。 从我国国情出发, 分析国内外各种因素和相关数据, 确定 我国合理的粮食储备规模主要应该考虑以下因素：一是我 国粮食储备应立足于国内, 以自力更生为主。二是首先满 足战略储备, 其次应有部分用于稳定市场调节, 还要有少 量机动使用。三是对储备粮进行动态管理, 适时地进行定 期轮换、推陈出新, 使储备粮始终保持良好的状态。从近 几年粮食储备体系运行看, 国家粮食储备制度的基本目标 应该以国家粮食安全为主, 稳定粮食市场价格为辅, 从这 一目标出发, 合理确定国家粮食储备规模。

\section{3 合理布局粮食储备库点}

根据我国地域广阔, 气候条件存在差异, 地区经济发 展不平衡等特点, 我国粮食储备库点的合理布局应从以下 几个方面进行考虑: 一是从地域分布考虑, 主要集中在中 东部地区。这些地区人口稠密, 经济比较发达, 对粮食的 社会需求旺盛, 粮食流通体系比较完备, 粮食流通速度也 比较快。这些地区的粮食储备应该靠近主销区和大中城市, 并且交通便利的地方, 但不应该位于大中城市, 以免影响 城市的扩大与发展。二是从国家粮食的战略储备和西部大 开发来考虑, 在中西部建一些储备库。内地和西部是我国 的腹地和战略后方，具有丰富的资源和广阔的开发前景。 现在我国的发展重心向西部转移, 人才也在逐步增加, 粮 食流通体系也要相应跟上。现在在中西部建一些储备库可 以作为战略储备之用, 将来西部发展了也可作为流通之用, 正可谓一举两得。三是从储备粮食品种来看, 应多储耐储
性好的粮种, 如小麦, 而避免或少储耐储性差的品种。当 然, 根据地区特点和各地不同的消费习惯, 各个品种合理 搭配还是十分必要的。四是应该加强研究我国储粮气候区 域的划分, 确定我国储备粮种的最佳分布。五是从经济的 角度出发, 因地制宜, 根据各地的经济和社会发展水平, 在不同地区建设适宜的仓型。

\section{4 健全储备粮调控协调机制}

政府相关部门既是中央储备粮宏观管理的决策者和参与 者，又是中国储备粮管理总公司经营管理的政策支持者和 监督者。有关部门要做到政企分开，应在有利于实现 “两 个确保” 的前提下，不要延续那种政府管企业的方式直接 插手中央储备粮微观管理和具体操作。要跳出传统思路, 完善中央储备粮的计划管理, 使其既具有严肃性, 又具有 灵活性，为中央储备粮实施调控创造良好的外部条件。要 充分发挥中储粮总公司的协调优势, 把政策性业务与非政 策性业务结合起来，把提供公共服务职能与提供市场服务 职能结合起来, 有助于最大程度地提高中国粮食市场的运 行效率。要尽快出台相关的配套管理规章制度, 为中央储 备粮管理提供充足的法律依据。一方面对中央储备粮管理 不善者和擅自动用者发挥法律威慑作用, 为中央储备粮数 量真实、质量完好提供法律保障。另一方面国务院各有关 部, 门要按照《条例》赋予的职责, 积极开展工作, 防止 部门之间由于认识不一致而出现决策延误和政策不连续, 给国家造成不应有的损失。要重点培育一批运行规范的全 国性和区域性粮食批发市场，完善市场功能，实现交易方 式创新, 严格市场管理制度, 为储备粮的高效吞吐轮换创 造市场条件。在此基础上, 还要研究利用期货市场的功能, 开展储备粮的套期保值，开辟储备粮食吞吐轮换的新渠道。 粮食批发市场和期货市场的价格对粮食供求十分敏感, 更 为重要的是可以影响社会公众对粮食价格的预期。

\section{5 加强粮食储备的硬件设施和软件支持的建设}

粮食储备的建设包括硬件设施的建设和软件支持。硬 件包括长期储备库、设施, 以及相关机械设备, 软件包括 组织机构、管理运行、粮食储藏技术和服务。应考虑转换 一下清仓查库的管理体制和机制，把粮库信息化建设深入 向前推进一步, 从入库到出库, 实行全过程信息追溯, 这 样既可以确保数量可靠、质量安全, 又可以把信息化与储 备体系建设结合起来，探索出一套信息化、现代化管理的 新办法。 


\section{6 加快粮食储备人才队伍建设}

采取多种方式培养和引进粮食储备经营管理人才以及 专业技术人才, 为粮食储备现代化发展提供智力支撑。采 取多种方式培养和引进粮食现代物流管理人才以及专业技 术人才, 为国家粮食储备体系的发展提供智力支撑。构建 合理的粮食储备人才激励机制, 加大人才引进支持力度。 为此, 要充分发挥高等教育的资源优势, 鼓励大专院校、 研究机构和企业合作, 尽快培养粮食储备的管理和技术人 才, 推动粮食储备体系现代化发展进程。

\section{参考文献(References)}

[1] Guoxiang Li, "Discussion on the Safety Risks of China's Grain and Its Control," Contemporary Economic Management May 2014Vol. 36 No.5
[2] Fu-ning ZHONG, "Can Grain Reserves and Price Control Stabilize the Food Market?" Journal of Nanjing Agricultural University (Social Sciences Edition) 2011. 11 ( 2)

[3] Jin Jia, "The Reasonable Size, the Layout and Macroscopical Adjusting Control of Our Country Grain Reserve," Chongqing Social Sciences 2012 (2)

[4] Juan WU and Ya-peng WANG, "Status and Strategies of Control System of Grain Reserves in China ," Research of Agricultural Modernization Nov. 2011 Vol. 32 No. 6

[5] Williams, J. C. and Wright, B. D, Storage and commodity markets, New York, Cambridge University Press, 1991.

[6] M. Fafchamps. Cash Crop Production, Food Price Volatility, and Rural Market Integration in the Third World. American Journal of Agricultural Economics, 1992. 